\title{
Erratum to: Prospective randomized trial comparing short-term antibiotic therapy versus standard therapy for acute uncomplicated sigmoid diverticulitis
}

\author{
Christine Schug-Pass • Pascal Geers • Omar Hügel • \\ Hans Lippert $\cdot$ Ferdinand Köckerling
}

Published online: 6 April 2010

(C) Springer-Verlag 2010

\section{Erratum to: Int J Colorectal Dis}

DOI 10.1007/s00384-010-0899-4

The original version of this article unfortunately contained a mistake. The presentation of the Methods in the abstract and the legend of Fig. 2 were incorrect. The corrected versions are given below.

Methods To compare the efficacy of short-term therapy (4 days) versus standard therapy (7 days) for uncomplicated sigmoid diverticulitis, a prospective randomized multicenter trial was conducted. Patients were randomized to treatment groups after 4 days. Both patient groups were monitored until discharge and were followed up after 4-6 weeks and 52 weeks. The results were standardized and statistically evaluated.

Fig. 2 Study flowchart: following enrolment in the study, 4-day therapy is first initiated with ertapenem; after investigating the success of treatment, patients are randomized to short- (4 days) or long-term therapy (7 days). Both groups continue to be monitored until discharged. Clinical examination is then conducted after 4-6 weeks and 52 weeks

The online version of the original article can be found at http://dx.doi. org/10.1007/s00384-010-0899-4.

C. Schug-Pass $(\bowtie) \cdot$ F. Köckerling

Department of Surgery, Center for Minimally Invasive Surgery,

Vivantes Hospital Spandau,

Neue Bergstrasse 6,

13585 Berlin, Germany

e-mail: christine.schug-pass@vivantes.de

P. Geers · O. Hügel

Department of Surgery, Center for Minimally Invasive Surgery,

Hannover Hospital Siloah,

Hannover, Germany

H. Lippert

Department of Surgery, Otto-von-Guericke-University,

Magdeburg, Germany 